\title{
REVIEW
}

\section{The role of mTOR pathway as target for treatment in adrenocortical cancer}

\author{
Maria Cristina De Martino ${ }^{1,2}$, Richard A Feelders' ${ }^{1}$, Claudia Pivonello ${ }^{2}$, Chiara Simeoli², Fortuna Papa ${ }^{2}$, \\ Annamaria Colao ${ }^{2}$, Rosario Pivonello ${ }^{2}$ and Leo J Hofland ${ }^{1}$
}

'Department of Internal Medicine, Erasmus Medical Center, Rotterdam, The Netherlands

2Dipartimento di Medicina Clinica e Chirurgia, Università Federico II, Naples, Italy

Correspondence should be addressed to M C De Martino: demartino.mc@gmail.com

\begin{abstract}
Adrenocortical carcinomas (ACCS) are rare tumors with scant treatment options for which new treatments are required. The MTOR pathway mediates the intracellular signals of several growth factors, including the insulin-like growth factors (IGFs), and therefore represents a potential attractive pathway for the treatment of several malignancies including ACCs. Several mTOR inhibitors, including sirolimus, temsirolimus and everolimus, have been clinically developed. This review summarizes the results of the studies evaluating the expression of the mTOR pathway components in ACCs, the effects of the mTOR inhibitors alone or in combination with other drugs in preclinical models of ACCs and the early experience with the use of these compounds in the clinical setting. The mTOR pathway seems a potential target for treatment of patients with ACC, but further investigation is still required to define the potential role of mTOR inhibitors alone or in combination with other drugs in the treatment of ACC patients.
\end{abstract}

\section{Key Words \\ - adrenal \\ - neuroendocrinology \\ - growth factors \\ - endocrine cancers}

\section{Introduction}

Adrenocortical carcinomas (ACCs) are rare tumors with scant treatment options for which new treatments are required $(1,2,3)$. The limited efficacy of conventional antineoplastic treatment in ACCs increases the need for novel effective treatment options. During the past 15 years, progress in understanding the pathogenesis of tumors has encouraged the development of so-called 'targeted drugs', which are compounds that specifically interfere with molecular mechanisms involved in tumor cell growth and/or tumor vascular supply, leading to major advances in oncology $(4,5)$.

Targeted drugs include compounds interfering with growth factor receptors and their related signaling pathways. Mammalian target of rapamycin (mTOR) is a protein kinase of the phosphoinositide 3 kinase (PI3Ks)/ protein kinase B (PKB or AKT) signaling pathway, which forms multimolecular intracellular complexes and functions as a gatekeeper of metabolism, as well as cell growth. mTOR receives signals from sensors of cell stress, intracellular nutrient levels and several growth factors, including vascular endothelial growth factor (VEGF), insulin-like growth factors (IGFs), epidermal growth factor (EGF) and platelet-derived growth factor (PDGF) $(6,7,8$, 9). mTOR can be part of the two functional complexes mTORC1 and mTORC2. Upon the binding of several growth factors to their cognate tyrosine kinase receptors, AKT is phosphorylated and activated, which in turn leads to the activation of MTOR as part of the mTORC1 complex. Activated mTORC1 complex regulates cell proliferation via the activation of mRNA translation and is mediated mainly via two downstream components, i.e. p70 ribosomal protein S6 kinase 1 (S6K1) and eukaryotic translation initiation factor $4 \mathrm{E}$ binding proteins (4EBP1). A more extensive description of this pathway has been previously reported and a schematic representation of the pathway is shown in Fig. $1(10,11,12,13)$. The mTORC2 


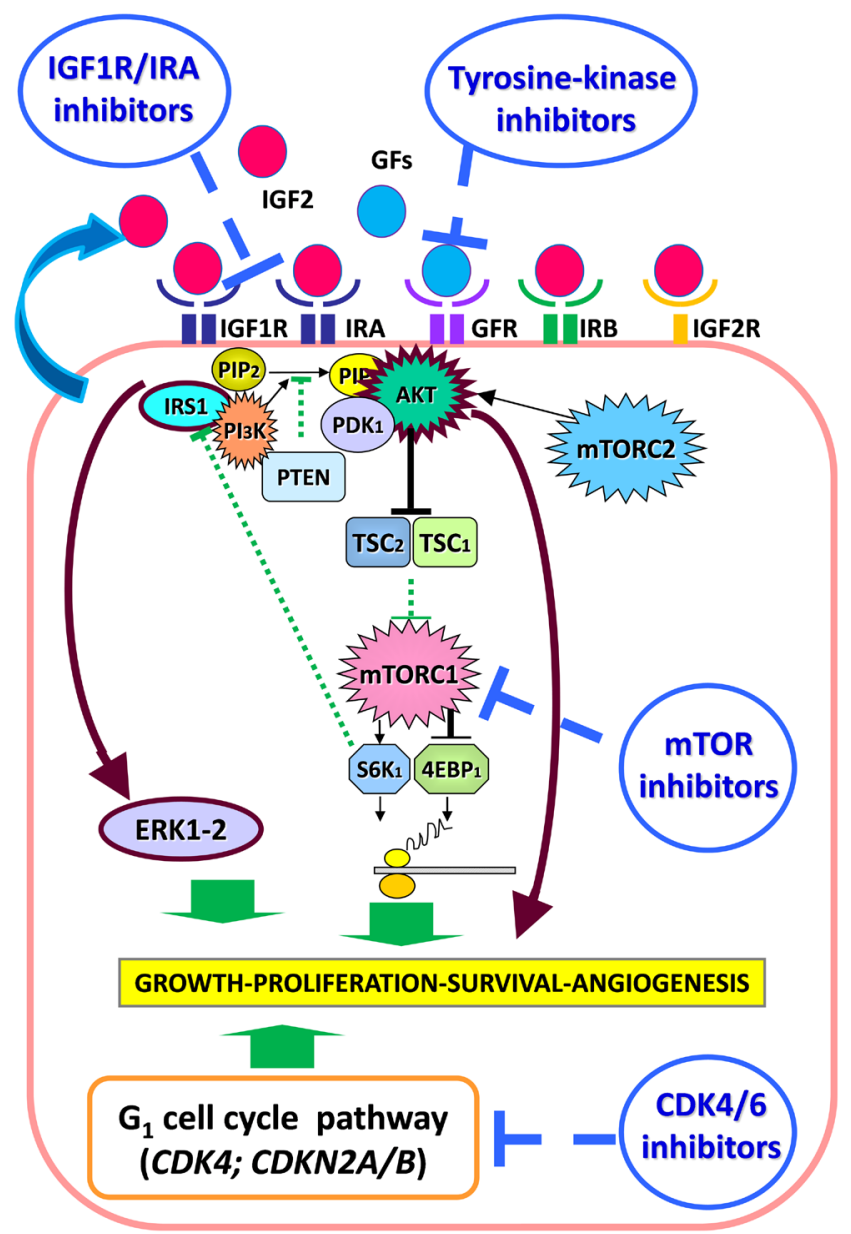

Figure 1

Schematic representation of the potential molecular pathways representing potential targets for treatment in patients with ACC, based on the results presented in the current review. GFs, growth factors; GFR, growth factor receptor. Brown lines show two potential escape pathways to the treatment with mTOR inhibitors: AKT and ERK activation.

complex regulates cytosketeton function and seems to be involved in the activation of AKT function $(10,11)$. Several drugs inhibiting the mTORC1 complex have been developed as anticancer treatment including sirolimus, temsirolimus and everolimus (traditional mTOR inhibitors), which have been approved for the treatment of different malignancy such as renal cell carcinoma and pancreatic neuroendocrine tumors $(14,15)$. More recently some compounds which also target the mTORC2 complex have been proposed as anticancer treatment (i.e. OSI-027, AZD2014) $(10,11)$. Alterations of growth factors and their cognate receptors are considered to be involved in the pathogenesis of ACCs $(16,17,18,19,20,21)$. Therefore, compounds interfering with tumor angiogenesis and growth factor signaling pathways represent a potential novel treatment option for the management of patients with ACCs. The mTOR pathway, being involved in both these processes, could represent a potential target for treatment of these malignancies $(2,22)$. Moreover, the most common molecular alteration observed in ACCs is the increased expression of IGF2 mRNA, which is reported in up to $90 \%$ of cases (22). Therefore, IGF2 has been suggested to be involved in the pathogenesis of ACCs and represents a potential target for treatment in this malignancy. Since the mTOR pathway is one of the main mediators of the intracellular effects of IGFs, the study of the mTOR pathway in ACCs has been considered attractive as potential target for treatment and to better understand the pathogenesis of these tumors (10).

This review aims at summarizing the results of the studies evaluating the expression of the mTOR pathway components in ACCs, the effects of the mTOR inhibitors alone or in combination with other drugs in preclinical models of ACCs and the early experience with the use of these compounds in the clinical setting. Our research group largely contributed to the current knowledge on the subject.

\section{The mTOR pathway in normal adrenals}

In the normal adrenal gland, a layer-specific protein expression pattern of the major components of the mTOR pathway has been found, suggesting a uncharacterized role of the mTOR pathway in particular adrenal functions. For example, the stronger expression of several components (i.e total-mTOR, total-/phospho-4EBP1 and total-/phospho-S6K1) of the mTOR pathway in the zona reticularis could suggest a role of this pathway in androgen production, and the stronger expression of these components in the zona glomerulosa may be related to angiotensin II-induced activation of the mTOR pathway (23). An anti-secretory effect (e.g. inhibition of cortisol production) of mTOR inhibitors in ACC cell lines has been reported (24), although up to date, signs or symptoms of hypoadrenalism with the use of mTOR inhibitors in the clinical setting have not been clearly described (14). Further studies are required to clarify the specific role of the mTOR pathway in regulating steroid production.

\section{Expression of the main components of the mTOR pathway in adrenocortical tumors}

The expression of the main components of the mTOR pathway in adrenocortical tumors (ACTs) has been

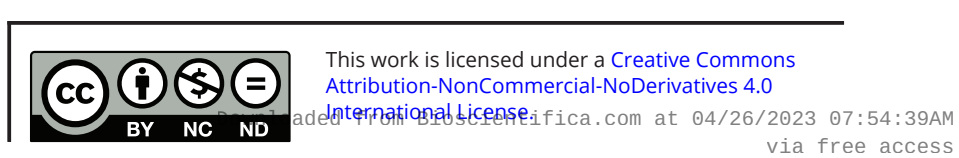


investigated in few studies $(10,25,26,27)$. Only one study evaluated the mRNA expression of mTOR, S6K1 and 4EBP1in a cohort of ACCs, demonstrating that the mRNA expression of S6K1 was significantly lower in ACCs than in benign ACTs (adrenocortical adenomas (ACAs)) (28). A highly variable protein expression of the main components of the mTOR pathway has been described in ACCs, and phospho-mTOR, phospho-S6K1 as well as phospho-4EBP1 were reported to be significantly expressed in 10-32, $30-59$ and $40-60 \%$ of cases respectively $(25,26,28)$. This is summarized in Table 1 . In the study by Nakamura et al., the mean protein expression of several components of the mTOR pathway was lower in ACC samples than in ACA or normal adrenal samples, although the statistics were not reported (26). Similarly in a study from our group, the protein expression of total and phosphomTOR, total and phospho-S6K1 and total and phospho4EBP1 was lower in ACCs compared to ACAs, although this difference was statistically significant only for total S6K1, and probably due to the small sample size (28). Even though these studies adopted different antibodies and methodologies, they all reported that the expression of the main phospho-proteins of the mTOR pathway are not constantly found in these tumors, suggesting that this pathway is activated only in a subgroup ACCs. These data are partially in contrast with the study by Doghman et al. who reported that mTOR signaling is active in childhood ACTs (29). These contrasting data further support the increasing body of evidence which suggests that adult ACCs and childhood ACTs are different entities. Based on these data, the mTOR pathway should not be expected to be widely involved in the pathogenesis of ACCs but might be involved in a subset of them.

Two studies investigated the potential prognostic value of the expression of some components of the mTOR pathway in ACTs (Table 1). We showed that S6K1 mRNA and protein expression are lower in ACCs than in ACAs, and ACC samples with a lower phosphoS6K1 and/or phospho-4EBP1 protein expression had a significantly higher Weiss score than others. Additionally ACCs with a higher mitotic count $(>5)$ presented a lower total S6K1 and phospho-4EBP1 protein expression (28). Recently Germano et al. observed a negative phosphomTOR staining in tumors with high Weiss score (25). In childhood ACTs, generally known to have a less aggressive phenotype than adult ACCs, Doghman et al. reported a positive expression of some components of mTOR pathway (29). These data suggested that a subset of less differentiated ACCs could have an inactivation of the mTOR pathway. Therefore, the downregulation of the
mTOR pathway in ACCs warrants further investigation as a potential prognostic factor.

In the era of personalized medicine, the description of the main components of the mTOR pathway in ACCs is an important step to explore, as their presence can be considered as potential markers for treatment with mTOR inhibitors. Considering that molecular biomarkers capable to predict the clinical response to mTOR inhibitors have not been clearly identified yet, the currently available studies suggest that a subset of patients have potential molecular evidence of mTOR pathway activation. However, further studies are required to explore whether these molecular events could predict an increased sensitivity to mTOR inhibitors.

\section{Effects of mTOR inhibitors in ACCs}

The testing of mTOR inhibitors in preclinical models of ACCs is a mandatory step to explore whether these compounds could represent a novel treatment opportunity for the management of ACCs. Few studies have evaluated the effects of different mTOR inhibitors, sirolimus, everolimus and/or temsirolimus on human ACC cancer cell lines (NCI-H295R, their clone HAC15 and SW13) and primary ACC cell cultures. Using different methodologies (Table 2), it was demonstrated that mTOR inhibitors inhibit the proliferation in ACC cell lines (including NCIH295R) (22, 24, 25, 28, 29, 30, 31). These compounds had stronger anti-proliferative effects in the SW13 cell line than in NCI-H295R $(25,28,29)$ and showed antiproliferative effects in some but not all ACC primary cell cultures $(28,29,30)$. However, it should be considered that while NCI-H295R cells are well accepted as a good model of ACCs, a debate is still open about the appropriateness of SW13 cells as a model for this type of cancer (32). Taking into account this and the other potential limitations of ACC cell lines as preclinical model of ACCs, the results of the current studies might suggest that among ACC patients it could be possible to find subgroups of patients with a higher sensitivity to mTOR inhibitors. The antiproliferative effects of mTOR inhibitors in ACC cells seem to be associated with cell cycle inhibition and/or apoptosis induction, although these effects have been observed only at high of the concentrations tested (24, 30). Based on current data the anti-proliferative effects of mTOR inhibitors at concentrations that are potentially reachable in vivo seem to be predominantly cytostatic (24). An anti-secretory effect of sirolimus in ACC cells has also been reported (24). In mice, the inhibition of

This work is licensed under a Creative Commons Attribution-NonCommercial-NoDerivatives 4.0 Internationab ticense.ifica com at $04 / 26 / 2023 \quad 07: 54: 39 A M$ 
Table 1 Studies reporting the protein expression (evaluated by immunohistochemistry) of the main components of the mTOR pathway in adrenocortical tumors. ACA, adrenocortical adenomas; ACC, adrenocortical carcinomas; IHC, immunohistochemistry; NA, normal adrenals.

\begin{tabular}{|c|c|c|}
\hline Author & $\begin{array}{l}\text { Number } \\
\text { of ACCs }\end{array}$ & Methodology \\
\hline $\begin{array}{r}\text { Nakamura } \\
\text { et al. (26) }\end{array}$ & 41 & $\begin{array}{l}\text { Standard IHC procedure. } \\
\text { Specimens were } \\
\text { categorized into six groups } \\
(0,0 \% ; 1,1-5 \% ; 2,6-25 \% ; 3 \text {, } \\
26-50 \% ; 4,51-75 \% ; 5 \text {, } \\
76-100 \%) \text {. }\end{array}$ \\
\hline $\begin{array}{c}\text { De Martino } \\
\text { et al. (28) }\end{array}$ & 20 & $\begin{array}{l}\text { Standard IHC procedure. The } \\
\text { score was calculated by the } \\
\text { sum of the intensity score } \\
\text { and the proportion of the } \\
\text { stained cells; this provided } \\
\text { a score between } 0 \text { and } 6 \text {. } \\
\text { The proportion score was } \\
\text { as follows: } 0=\text { no positivity } \\
\text { (or }<10 \% \text { ); }+1 \leq 1 / 3 \text { tumor } \\
\text { cell positivity; }+2=1 / 3-2 / 3 \\
\text { tumor cell positivity; and } \\
+3=\text { more than } 2 / 3 \text { tumor } \\
\text { cell positivity. The intensity } \\
\text { score was as follows: }+1 \\
\text { weak staining; }+2 \\
\text { intermediate staining; and } \\
+3 \text { strong staining. The } \\
\text { score } 0 \text { was considered as } \\
\text { negative, } 2-3 \text { as low, } 4-5 \text { as } \\
\text { intermediate, and } 6 \text { as high. } \\
\text { Finally, adrenocortical } \\
\text { tumors were dichotomously } \\
\text { grouped as having } \\
\text { intermediate to high } \\
\text { expression of the evaluated } \\
\text { protein and } \\
\text { phosphoproteins (IHC score } \\
\geq 4 \text { ) or not (IHC score }<4 \text { ). } \\
\text { The reported percentages } \\
\text { of positive ACC cases refer } \\
\text { to the percentage of cases } \\
\text { having intermediate to high } \\
\text { expression of the evaluated } \\
\text { proteins. }\end{array}$ \\
\hline
\end{tabular}

mTOR monoclonal;

Phospho-mTOR

(Ser2448) monoclonal;

p70 S6 Kinase

monoclonal;

Phoapho-p70 S6 Kinase

(Thr389) monoclonal

4E-BPI monoclonal;

Phospho-4E-BPI(Ser65)

monoclonal

\section{Phospho-Akt: \\ Kinase:} positive ACC

cases (\%)

positive ACC

cases $(\%)$

cases (\%)

ACC cases (\%)

positive ACC

Not evaluated

cases $(\%)$

monoclonal; phospho-

polyclonal; Phoapho-p70

monoclonal; Phospho-S6

omal Protein

Phospho-4E-BP1(Thr70)

polyclonal

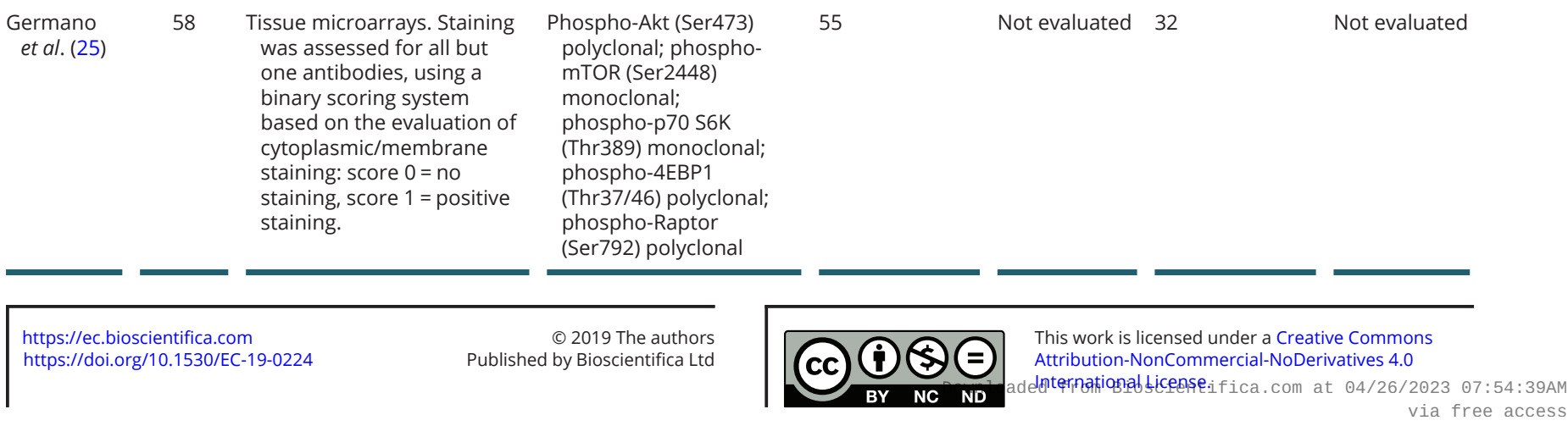

mTOR (Ser2448)

monoclonal;

phospho-p70 S6K

(Thr389) monoclonal;

phospho-4EBP1

(Thr37/46) polyclonal;

phospho-Raptor

(Ser792) polyclonal 


\begin{tabular}{|c|c|c|c|c|c|}
\hline $\begin{array}{l}\text { Phoapho-p70 } \\
\text { S6 Kinase: } \\
\text { positive ACC } \\
\text { cases (\%) }\end{array}$ & $\begin{array}{l}\text { Phospho-S6 } \\
\text { Ribosomal } \\
\text { Protein: } \\
\text { positive ACC } \\
\text { cases (\%) }\end{array}$ & $\begin{array}{l}\text { 4E-BP1: } \\
\text { positive ACC } \\
\text { cases }(\%)\end{array}$ & $\begin{array}{l}\text { Phospho-4E-BP1: } \\
\text { positive ACC } \\
\text { cases }(\%)\end{array}$ & $\begin{array}{l}\text { Phospho-Raptor: } \\
\text { positive ACC } \\
\text { cases }(\%)\end{array}$ & $\begin{array}{l}\text { Comparison with } \\
\text { ACA }\end{array}$ \\
\hline Not reported & Not reported & Not evaluated & Not reported & Not evaluated & $\begin{array}{l}\text { With the exception } \\
\text { of phospho-Akt, all } \\
\text { the evaluated } \\
\text { proteins were } \\
\text { found to have a } \\
\text { mean expression } \\
\text { tendentially lower } \\
\text { in ACC than in ACA, } \\
\text { although the } \\
\text { significance is not } \\
\text { reported }\end{array}$ \\
\hline 30 & Not evaluated & 75 & 60 & Not evaluated & $\begin{array}{l}\text { All the evaluated } \\
\text { proteins were } \\
\text { found to have a } \\
\text { mean expression } \\
\text { tendentially lower } \\
\text { in ACC than in ACA. } \\
\text { This difference was } \\
\text { significant only for } \\
\text { p70 S6 Kinase } \\
(P=0.009)\end{array}$ \\
\hline
\end{tabular}

Comparison with NA

All the evaluated proteins were found to have a mean expression tendentially lower in ACC than in NA, although the significance is not reported

Not evaluated

$$
\begin{aligned}
& \text { In ACC group, a } \\
& \text { higher p70 S6 } \\
& \text { Kinase } \\
& (P=0.04) \text { and } \\
& \text { phospho-4EBP1 } \\
& (P=0.04) \\
& \text { protein } \\
& \text { expression } \\
& \text { were observed } \\
& \text { in tumors } \\
& \text { having a mitotic } \\
& \text { count }<5
\end{aligned}
$$



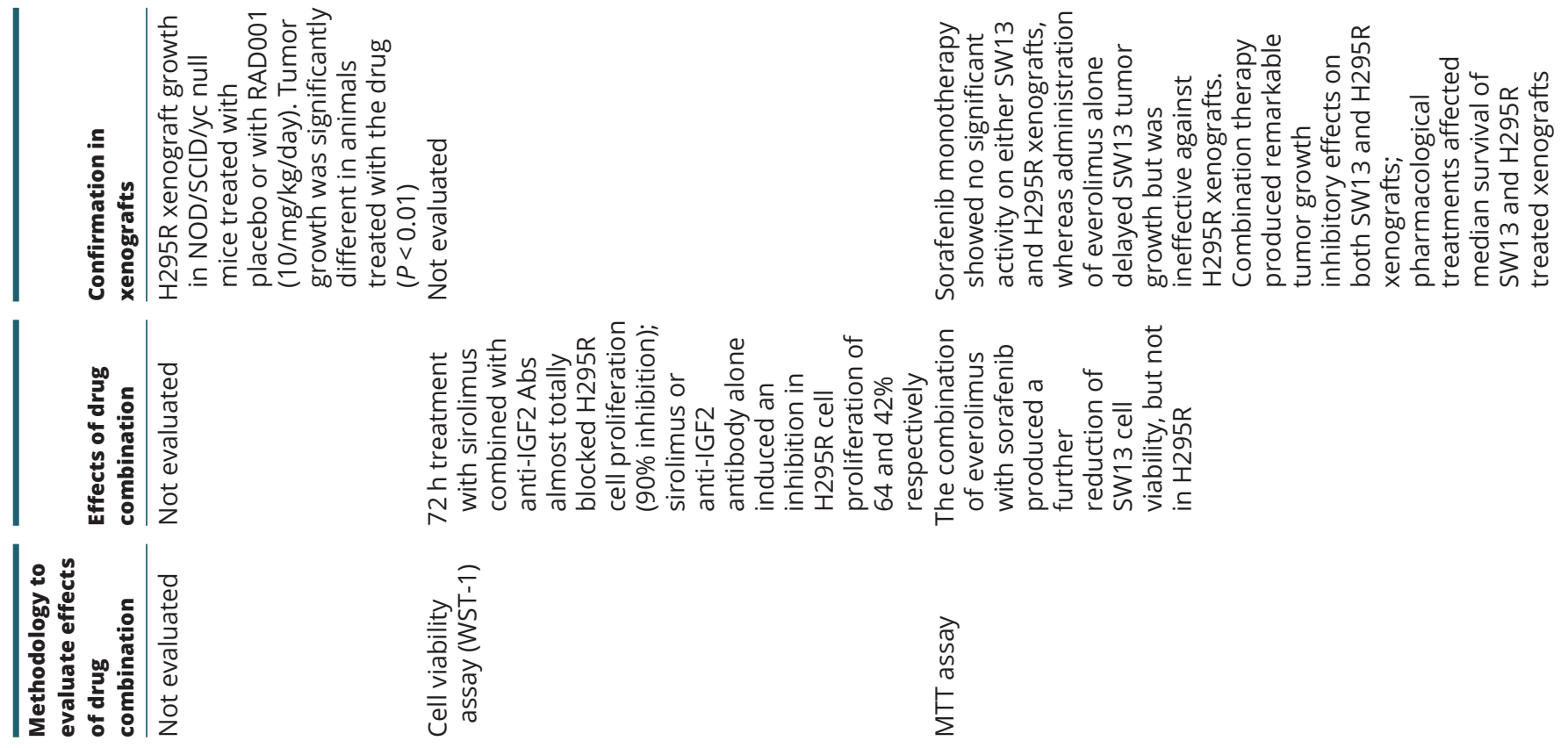

$$
\begin{aligned}
& \text { ब్ } \\
& \text { ஸे } \\
& \stackrel{5}{\Sigma}
\end{aligned}
$$

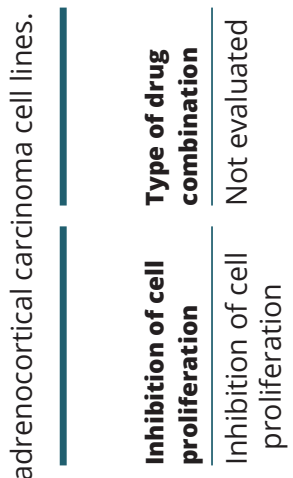

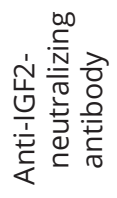
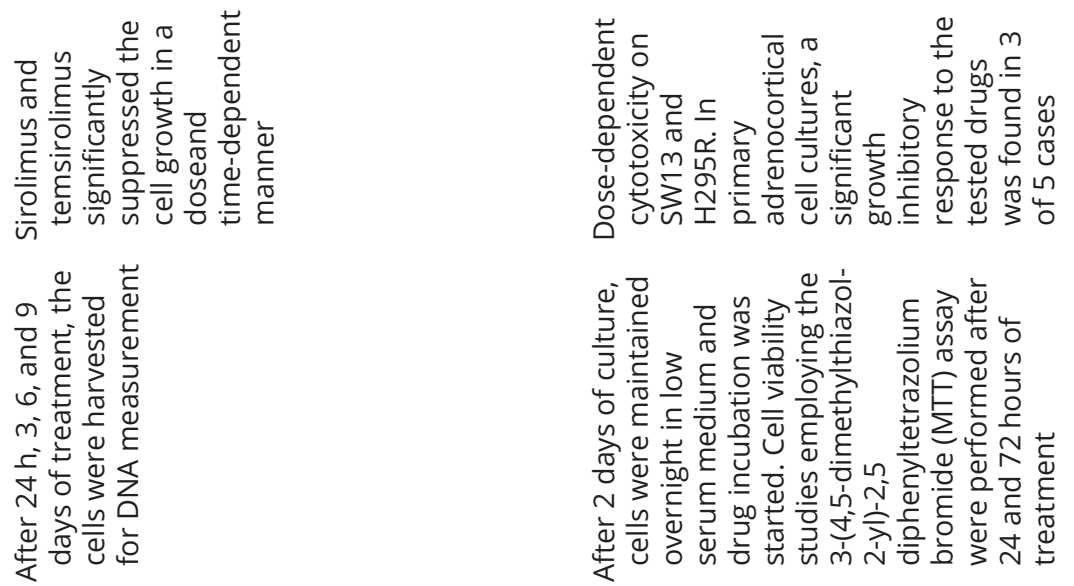

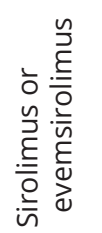

है

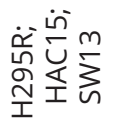

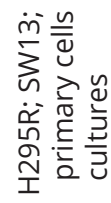

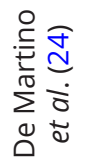

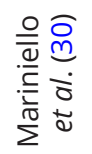

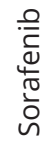




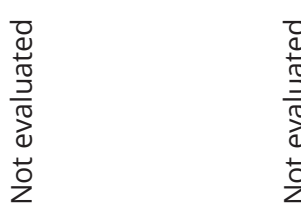

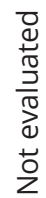

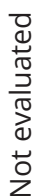

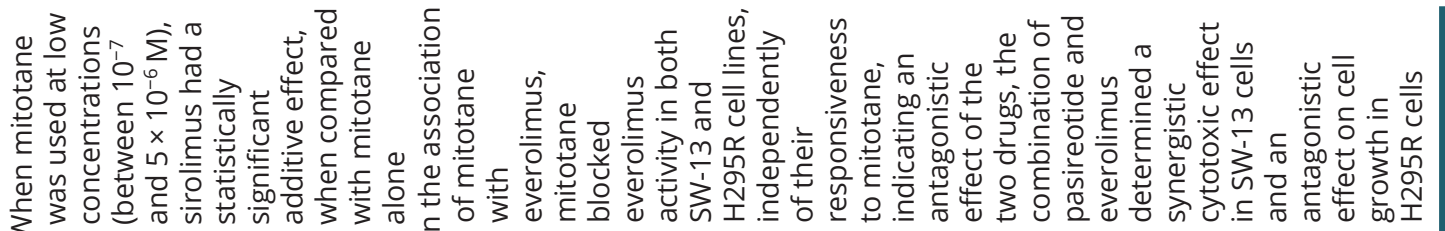

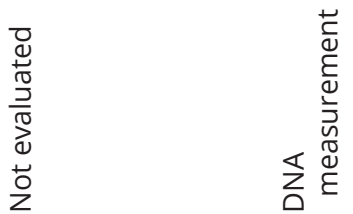

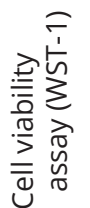

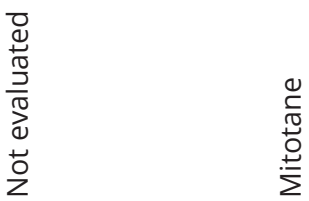

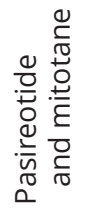

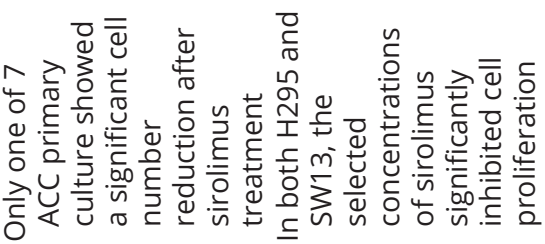

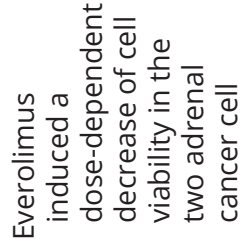

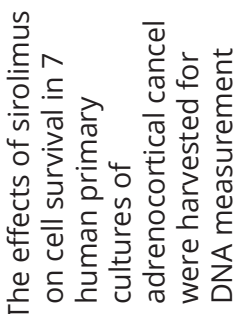
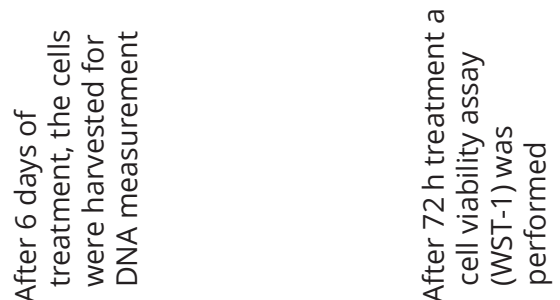

$\begin{array}{ll}\stackrel{n}{\underline{\underline{E}}} & \stackrel{n}{\text { है }} \\ \text { in } & \text { in }\end{array}$

$\frac{\text { ?ำ }}{\text { है }}$

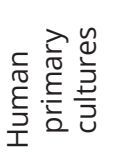

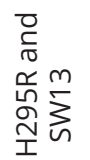

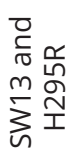

\begin{tabular}{|c|}
\hline 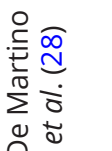 \\
\hline
\end{tabular}

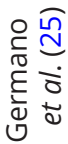



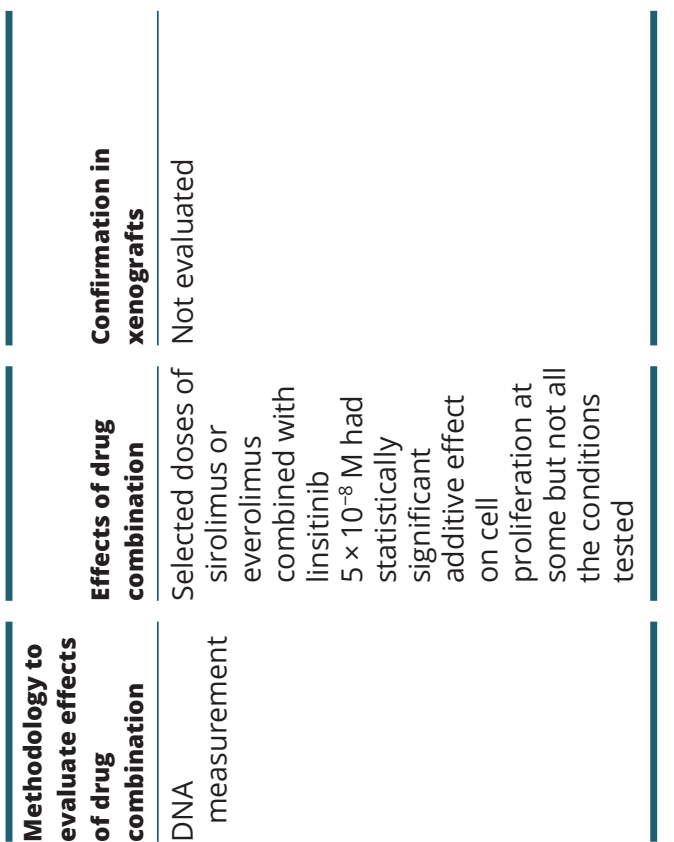

NCI-H295R xenograft growth has been reported using high everolimus dose (29). Additionally, sirolimus was found to significantly reduce cell survival and cortisol secretion only in selected ACC primary cultures (28). These data suggest that a subset of patients with ACCs might be more sensitive than others to this treatment. Therefore, further studies are warranted to find potential biomarkers predictive of response to treatment with mTOR inhibitors in ACCs. In this respect, the protein expression of the main components of the mTOR pathway was investigated in relation to the in vitro effects of mTOR inhibitors in ACC primary cultures (28). However, the expression of none of the evaluated proteins correlated with the in vitro response to these drugs (28). This absence of a correlation could be due to the low number of primary cultures used in this study. However, specifically designed clinical trials can appropriately evaluate for biomarkers predictive of response to treatments. Unfortunately, this type of clinical trials is extremely difficult to perform in such a rare cancer as ACCs. Therefore, progress in this direction can only be awaited from the results of clinical trials in other more common types of cancer. Once a clear predictive biomarker is identified in other cancers, its value in ACCs should be explored.

To the best of our knowledge, the effects of compounds targeting the mTORC1 and 2 complex in ACC cell lines have not been explored yet. A recent study reported that n-3 polyunsaturated fatty acids prevent ACC growth by inhibiting mTORC1/2 in preclinical models of ACCs, which suggests that both mTORC complexes might play a role in ACC cell proliferation (33). Another compound that was reported to inhibit ACC growth in preclinical models of ACCs is the dual PI3-kinase/mTOR inhibitor NVP-BEZ235 (34). These new class of compounds require future investigations.

\section{Relationship between the mTOR and the IGF pathways in ACCs}

The relationship between the mTOR and the IGF pathways in ACCs has been scantly investigated (10). As the mTOR pathway mediates some of the IGF effects $(10,35,36)$, it could be involved in mediating the pathogenic effects of IGFs in ACCs. Therefore it might be important to understand whether a differential expression of the main components of the IGF pathway could influence the in vitro sensitivity to mTOR inhibitors and whether there is a rational to combine drugs targeting the IGF and the mTOR pathways. 
The relationship between the mTOR- and the IGF pathways in the NCI-H295R and SW13 ACC cell lines is addressed in a few studies $(24,28)$. These studies demonstrate that both ACC cell lines have a similar protein expression of IGF1R and the main components of the mTOR pathway, but both mRNA and protein expression of IGF2 were considerably higher in NCI-H295R compared with SW13. IGF1 significantly stimulated AKT and S6K1 phosphorylation in both NCI-H295R and SW13, demonstrating that the mTOR pathway acts as an intracellular mediator of IGFs in both human ACC cell lines (24). A schematic representation of the pathway is shown in Fig. 1. Therefore, the mTOR pathway could also be involved in mediating the proliferative effects of IGFs in ACC cell lines. However, the effects of the mTOR inhibitor sirolimus on the IGF-activated intracellular pathways were different between NCI-H295R and SW13 cells. At the experimental condition tested, IGF1 induced the activation of the AKT/mTOR pathway in both cell lines, but ERK activation was observed only in NCI-H295R. Sirolimus efficiently suppressed the mTORC1 activity in both cell lines. However, only in NCI-H295R cells, the inhibition of mTORC1 activity was associated with the activation of AKT, likely representing an escape pathway. This activation was further enhanced by IGF1 administration which also induced ERK stimulation in the sirolimus-treated NCI-H295R cells. Therefore, the NCI-H295R cell line seems to have two potential pathways of escape to treatment with traditional mTOR inhibitors: the AKT and ERK pathways (see Fig. 1 for the potential escape pathways) $(35,37)$. The activation of these escape pathways could be related, at least partially, to the IGF2 overexpression in NCI-H295R, which is not found in the SW13 cell model. Therefore, it could be speculated that high IGF2 expression could negatively influence the in vitro sensitivity of ACC cell lines to mTOR inhibitors, which supports the rationale to combine mTOR inhibitors and drugs specifically targeting the IGF pathway in ACCs (31). In another study everolimus has been reported to inhibit S6K1 phosphorylation in both NCI-H295R and SW13, to only slightly reduce AKT phosphorylation at the highest drug concentration used and to have no effect on ERK phosphorylation (30). High everolimus doses might reduce AKT phosphorylation sequestering of the mTOR as part of the mTORC1 complex and subsequently inhibiting the mTORC2 activity (10).

IGF2 overexpression is very common in ACC (about 80\%) (18), whereas only a subset of ACC samples strongly expressed the components of the mTOR pathway, particularly the phospho-proteins (28). In the studies from our research group a subgroup of 16 ACC samples was characterized for protein expression of the main components of both mTOR and IGF pathway, including IGF2 $(28,31)$. Within this subgroup of ACC samples, we were not able to find correlations between these proteins (Table 3; personal unpublished data). Therefore, the expression of the main components of the mTOR and the IGF pathways seem not to be strongly related, which raises the questions whether in ACCs there is a dissociation between the expression of IGF2 and the activation of the classical IGF stimulated intracellular pathways, and whether the role of IGF2 in the pathogenesis of adult ACCs may have been overestimated, in agreement with some other recent speculations (38). However, it should also be considered that the complexity of the IGF system may have been underestimated since ACC expresses other components of the IGF pathway as well, such as the insulin receptor subtype A and the IGF2R $(31,36)$. These components have been scantly considered up today. As such, before finally declaring a 'game over' (38) for the role of IGF2 in adrenocortical tumorigenesis and as a potential target for novel treatment in ACC patients, it could be probably useful to return to the bench and try to better explore the IGF pathway in ACCs in its whole complexity.

\section{Effects of mTOR inhibitors in combination with other drugs in ACTs}

The data derived from the use of the mTOR inhibitors alone in preclinical studies $(24,25,28-30)$, together with the expected heterogeneity of ACCs $(25,28,39)$, suggest that caution is required before using this class of drugs in unselected ACC patients. Such caution was also suggested by preliminary clinical experience with the use of everolimus in some ACC patients with a late stage of disease (40). Unfortunately, due to the current lack of molecular biomarkers capable to predict the response to mTOR inhibitors in ACCs $(25,28)$, it is difficult to define selection criteria for ACC patients that are candidate for treatment with this class of drugs. Therefore, combination of mTOR inhibitors with other drugs, potentially active in ACCs, could be a more prudent clinical approach than the use of these inhibitors as monotherapy in unselected ACC patients.

Until recently, the IGF pathway was considered as the most attractive target for new treatment in ACCs $(10,41,42)$ with a potential rationale to combine mTOR inhibitors with drugs targeting the IGF pathway $(11,24)$.

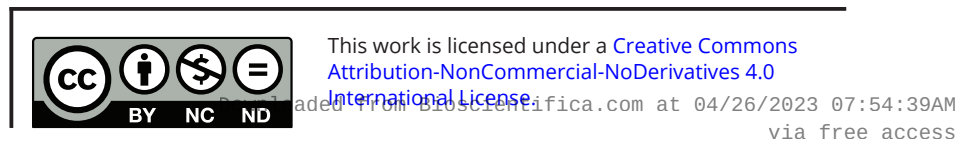



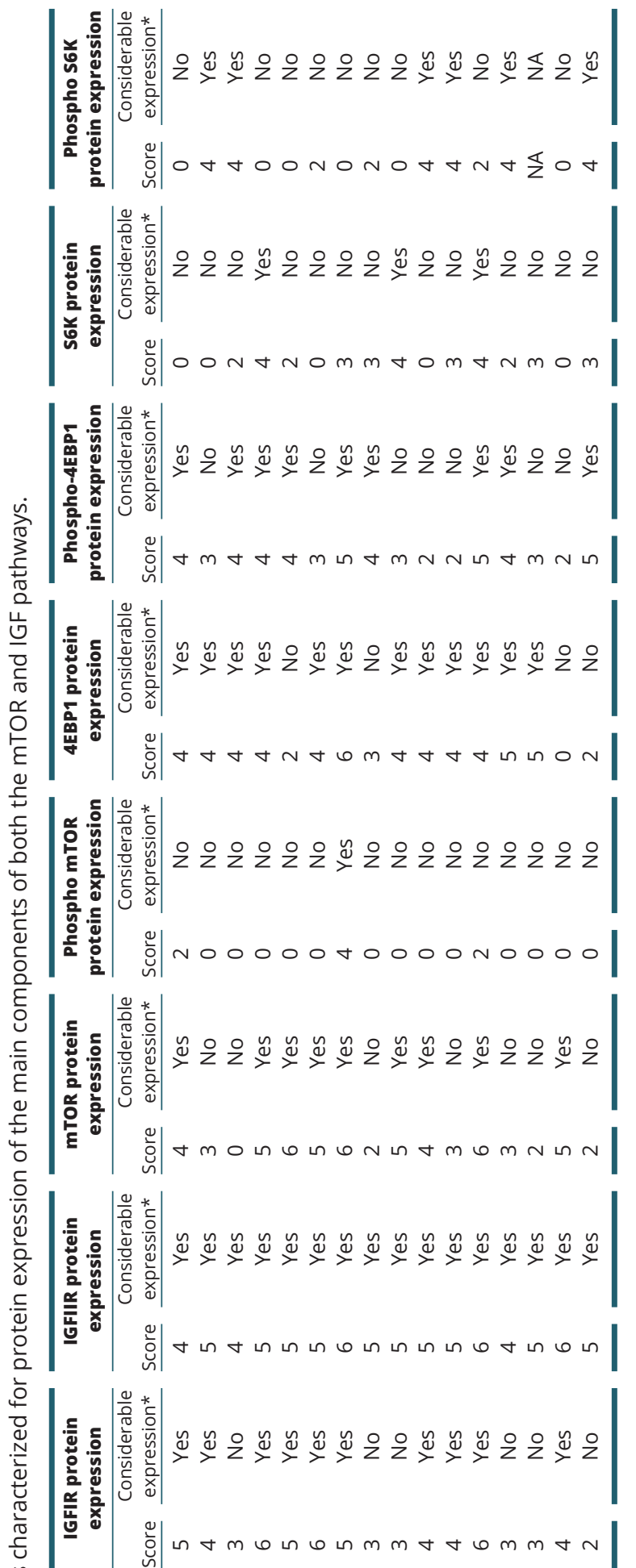
in their main final conclusions, both studies show that the effects of mitotane can, at least in some conditions, overcome the effects of the mTOR inhibitors thus limiting the usefulness of combining full doses of these two therapeutic agents. As mentioned earlier, the preclinical results show that the addition of sirolimus to low concentrations of mitotane has stronger anti-proliferative effects than mitotane alone (22). If these results could be translated to humans, they suggest that the addition of sirolimus might add to the antitumor action of mitotane, thereby reducing the mitotane dose required to obtain a desired clinical effect with potentially fewer side effects. In a clinical setting, mTOR inhibitors can be metabolized 
by the microsomal liver enzyme cytochrome P450 (CYP3A4/5). Drugs as mitotane are capable to induce these enzymes, and might increase the liver metabolization of mTOR inhibitors, potentially reducing the plasma concentration of these compounds to sub-therapeutic levels $(44,48)$. The combination of the mTOR inhibitor everolimus and the tyrosine kinase inhibitor sorafenib has been evaluated in preclinical models of ACCs in which it is shown that combined treatment was more effective than single drug treatment both in ACC cell lines and in xenograft models. These data support the rationale for combined treatment in this type of malignancy (30).

\section{New potential targets for ACCs in addition to the IGF and mTOR pathways}

Until today, most of the early clinical experience with targeted drugs, including drugs targeting the IGF pathway, failed to demonstrate the desired effects in patients with ACCs $(2,38,43)$. This raises the question whether molecular events, potentially targetable with currently developed drugs, are present in at least a subset of ACC patients. Using hotspot gene sequencing and comparative genomic hybridization, the presence of a large number of mutations and copy number abnormalities of potential interest for therapeutic aims, were evaluated in a large group of adult ENSAT stage III-IV ACC samples. No relevant alteration in the evaluated components of the mTOR and IGF pathways were found with these techniques and no simple targetable molecular event emerged (21, 39). Therefore, based on genomic alterations, the cell cycle appeared to be the most relevant new potential therapeutic target for patients with advanced ACC (Fig. 1). Recent data from exome sequencing confirm that the cell cycle or WNT pathways might be future target for treatment in ACCs $(20,49)$. Further studies to explore the effects of these compounds in preclinical models of ACCs are warranted.

Overall current data underline that, despite the fact that during the last 10 years much progress has been made in describing the molecular alteration in ACCs, the translation of these progress from bench to the bedside with the aim to improve the treatment of patients with ACCs has not been easy, so far.

\section{Conclusion and future directions}

In conclusion, the mTOR pathway seems a potential target for treatment of a subset of patients with ACCs, but treatment strategies combining mTOR inhibitors with other drugs are expected be more effective than the use of mTOR inhibitors alone. Additionally, considering the potential heterogeneity of this malignancy, treatment strategies based on the selection of patients with a potentially higher chance to respond to mTOR inhibitors according to their tumor characteristics, might be more effective than the use of mTOR inhibitors in unselected patients. Unfortunately, molecular biomarkers capable to predict a clinical response to mTOR inhibitors have not been clearly identified yet. Therefore, further preclinical and clinical investigations are required to find new molecular biomarkers useful to predict tumor response to both conventional and novel treatments for patients with ACCs and to address the role of mTOR inhibitors, alone or in combination with other drugs, in selected subgroups of patients with these tumors. All these data could help to move into the direction of a more personalized approach to the treatment of ACCs, and hopefully this approach could lead to progress in the clinical management of this rare but aggressive disease.

\section{Declaration of interest}

The authors declare that there is no conflict of interest that could be perceived as prejudicing the impartiality of this review.

\section{Funding}

This work did not receive any specific grant from any funding agency in the public, commercial or not-for-profit sector.

\section{References}

1 Fassnacht M, Dekkers OM, Else T, Baudin E, Berruti A, de Krijger R, Haak HR, Mihai R, Assie G \& Terzolo M. European Society of Endocrinology Clinical Practice Guidelines on the management of adrenocortical carcinoma in adults, in collaboration with the European Network for the Study of Adrenal Tumors. European Journal of Endocrinology 2018179 G1-G46. (https://doi.org/10.1530/EJE-180608)

2 Else T, Kim AC, Sabolch A, Raymond VM, Kandathil A, Caoili EM, Jolly S, Miller BS, Giordano TJ \& Hammer GD. Adrenocortical carcinoma. Endocrine Reviews 201435 282-326. (https://doi. org/10.1210/er.2013-1029)

3 Creemers SG, Hofland LJ, Korpershoek E, Franssen GJ, van Kemenade FJ, de Herder WW \& Feelders RA. Future directions in the diagnosis and medical treatment of adrenocortical carcinoma. Endocrine-Related Cancer 201623 R43-R69. (https://doi.org/10.1530/ ERC-15-0452)

4 Piccart-Gebhart MJ, Procter M, Leyland-Jones B, Goldhirsch A, Untch M, Smith I, Gianni L, Baselga J, Bell R, Jackisch C, et al. Trastuzumab after adjuvant chemotherapy in HER2-positive breast cancer. New England Journal of Medicine 2005353 1659-1672. (https://doi.org/10.1056/NEJMoa052306)

5 Paez JG, Janne PA, Lee JC, Tracy S, Greulich H, Gabriel S, Herman P, Kaye FJ, Lindeman N, Boggon TJ, et al. EGFR mutations in lung 
cancer: correlation with clinical response to gefitinib therapy. Science 2004304 1497-1500. (https://doi.org/10.1126/science.1099314)

6 Hanna SC, Heathcote SA \& Kim WY. mTOR pathway in renal cell carcinoma. Expert Review of Anticancer Therapy 20088 283-292. (https://doi.org/10.1586/14737140.8.2.283)

7 Wan X \& Helman LJ. The biology behind mTOR inhibition in sarcoma. Oncologist 200712 1007-1018. (https://doi.org/10.1634/ theoncologist.12-8-1007)

8 Konings IR, Verweij J, Wiemer EA \& Sleijfer S. The applicability of mTOR inhibition in solid tumors. Current Cancer Drug Targets 20099 439-450. (https://doi.org/10.2174/156800909788166556)

9 Le Tourneau C, Faivre S, Serova M \& Raymond E. mTORC1 inhibitors: is temsirolimus in renal cancer telling us how they really work? British Journal of Cancer 200899 1197-1203. (https://doi. org/10.1038/sj.bjc.6604636)

10 De Martino MC, Van Koetsveld PM, Pivonello R \& Hofland LJ. Role of the mTOR pathway in normal and tumoral adrenal cells. Neuroendocrinology 201092 28-34. (https://doi. org/10.1159/000314280)

11 Robbins HL \& Hague A. The PI3K/Akt pathway in tumors of endocrine tissues. Frontiers in Endocrinology 20156 188. (https://doi. org/10.3389/fendo.2015.00188)

12 Bahrami A, Khazaei M, Hasanzadeh M, ShahidSales S, Joudi Mashhad M, Farazestanian M, Sadeghnia HR, Rezayi M, Maftouh M, Hassanian SM, et al. Therapeutic potential of targeting PI3K/AKT pathway in treatment of colorectal cancer: rational and progress. Journal of Cellular Biochemistry 2018119 2460-2469. (https://doi. org/10.1002/jcb.25950)

13 Eyre TA, Collins GP, Goldstone AH \& Cwynarski K. Time now to TORC the TORC? New developments in mTOR pathway inhibition in lymphoid malignancies. British Journal of Haematology 2014166 336-351. (https://doi.org/10.1111/bjh.12945)

14 Hudes G, Carducci M, Tomczak P, Dutcher J, Figlin R, Kapoor A, Staroslawska E, Sosman J, McDermott D, Bodrogi I, et al. Temsirolimus, interferon alfa, or both for advanced renal-cell carcinoma. New England Journal of Medicine 2007356 2271-2281. (https://doi.org/10.1056/NEJMoa066838)

15 Yao JC, Shah MH, Ito T, Bohas CL, Wolin EM, Van Cutsem E, Hobday TJ, Okusaka T, Capdevila J, de Vries EG, et al. Everolimus for advanced pancreatic neuroendocrine tumors. New England Journal of Medicine 2011364 514-523. (https://doi.org/10.1056/ NEJMoa1009290)

16 Volante M, Buttigliero C, Greco E, Berruti A \& Papotti M. Pathological and molecular features of adrenocortical carcinoma: an update. Journal of Clinical Pathology 200861 787-793. (https://doi. org/10.1136/jcp.2007.050625)

17 Fassnacht M, Kreissl MC, Weismann D \& Allolio B. New targets and therapeutic approaches for endocrine malignancies. Pharmacology and Therapeutics 2009123 117-141. (https://doi.org/10.1016/j. pharmthera.2009.03.013)

18 Lerario AM, Moraitis A \& Hammer GD. Genetics and epigenetics of adrenocortical tumors. Molecular and Cellular Endocrinology 2014386 67-84. (https://doi.org/10.1016/j.mce.2013.10.028)

19 Zheng S, Cherniack AD, Dewal N, Moffitt RA, Danilova L, Murray BA, Lerario AM, Else T, Knijnenburg TA, Ciriello G, et al. Comprehensive pan-genomic characterization of adrenocortical carcinoma. Cancer Cell 201629 723-736. (https://doi.org/10.1016/j.ccell.2016.04.002)

20 Assie G, Letouze E, Fassnacht M, Jouinot A, Luscap W, Barreau O, Omeiri H, Rodriguez S, Perlemoine K, Rene-Corail F, et al. Integrated genomic characterization of adrenocortical carcinoma. Nature Genetics 201446 607-612. (https://doi.org/10.1038/ng.2953)

21 Lippert J, Appenzeller S, Liang R, Sbiera S, Kircher S, Altieri B, Nanda I, Weigand I, Gehrig A, Steinhauer S, et al. Targeted molecular analysis in adrenocortical carcinomas: a strategy toward improved personalized prognostication. Journal of Clinical Endocrinology and
Metabolism 2018103 4511-4523. (https://doi.org/10.1210/jc.201801348)

22 De Martino MC, van Koetsveld PM, Feelders RA, Lamberts SWJ, de Herder WW, Colao A, Pivonello R \& Hofland LJ. Effects of combination treatment with sirolimus and mitotane on growth of human adrenocortical carcinoma cells. Endocrine 201652 664-667. (https://doi.org/10.1007/s12020-015-0818-0)

23 Nazarewicz RR, Salazar G, Patrushev N, San Martin A, Hilenski L, Xiong S \& Alexander RW. Early endosomal antigen 1 (EEA1) is an obligate scaffold for angiotensin II-induced, PKC-alpha-dependent Akt activation in endosomes. Journal of Biological Chemistry 2011286 2886-2895. (https://doi.org/10.1074/jbc.M110.141499)

24 De Martino MC, van Koetsveld PM, Feelders RA, Sprij-Mooij D, Waaijers M, Lamberts SW, de Herder WW, Colao A, Pivonello R \& Hofland LJ. The role of mTOR inhibitors in the inhibition of growth and cortisol secretion in human adrenocortical carcinoma cells. Endocrine-Related Cancer 201219 351-364. (https://doi.org/10.1530/ ERC-11-0270)

25 Germano A, Rapa I, Duregon E, Votta A, Giorcelli J, Buttigliero C, Scagliotti GV, Volante M, Terzolo M \& Papotti M. Tissue expression and pharmacological in vitro analyses of mTOR and sstr pathways in adrenocortical carcinoma. Endocrine Pathology 201728 95-102. (https://doi.org/10.1007/s12022-017-9473-8)

26 Nakamura M, Miki Y, Akahira J, Morimoto R, Satoh F, Ishidoya S, Arai Y, Suzuki T, Hayashi Y \& Sasano H. An analysis of potential surrogate markers of target-specific therapy in archival materials of adrenocortical carcinoma. Endocrine Pathology 200920 17-23. (https://doi.org/10.1007/s12022-009-9058-2)

27 Fassnacht M, Weismann D, Ebert S, Adam P, Zink M, Beuschlein F, Hahner S \& Allolio B. AKT is highly phosphorylated in pheochromocytomas but not in benign adrenocortical tumors. Journal of Clinical Endocrinology and Metabolism 200590 4366-4370. (https://doi.org/10.1210/jc.2004-2198)

28 De Martino MC, Feelders RA, de Herder WW, van Koetsveld PM, Dogan F, Janssen JA, Waaijers AM, Pivonello C, Lamberts SW, Colao A, et al. Characterization of the mTOR pathway in human normal adrenal and adrenocortical tumors. Endocrine-Related Cancer 201421 601-613. (https://doi.org/10.1530/ERC-13-0112)

29 Doghman M, El Wakil A, Cardinaud B, Thomas E, Wang J, Zhao W, Peralta-Del Valle MH, Figueiredo BC, Zambetti GP \& Lalli E. Regulation of insulin-like growth factor-mammalian target of rapamycin signaling by microRNA in childhood adrenocortical tumors. Cancer Research 201070 4666-4675. (https://doi. org/10.1158/0008-5472.CAN-09-3970)

30 Mariniello B, Rosato A, Zuccolotto G, Rubin B, Cicala MV, Finco I, Iacobone M, Frigo AC, Fassina A, Pezzani R, et al. Combination of sorafenib and everolimus impacts therapeutically on adrenocortical tumor models. Endocrine-Related Cancer 201219 527-539. (https:// doi.org/10.1530/ERC-11-0337)

31 De Martino MC, van Koetsveld PM, Feelders RA, de Herder WW, Dogan F, Janssen JAMJL, Hofste Op Bruinink D, Pivonello C, Waaijers AM, Colao A, et al. IGF and mTOR pathway expression and in vitro effects of linsitinib and mTOR inhibitors in adrenocortical cancer. Endocrine 201964 673-684. (https://doi.org/10.1007/s12020019-01869-1)

32 Wang T \& Rainey WE. Human adrenocortical carcinoma cell lines. Molecular and Cellular Endocrinology 2012351 58-65. (https://doi. org/10.1016/j.mce.2011.08.041)

33 Liu J, Xu M, Zhao Y, Ao C, Wu Y, Chen Z, Wang B, Bai X, Li M \& Hu W. n-3 polyunsaturated fatty acids abrogate mTORC1/2 signaling and inhibit adrenocortical carcinoma growth in vitro and in vivo. Oncology Reports 201635 3514-3522. (https://doi.org/10.3892/ or.2016.4720)

34 Doghman M \& Lalli E. Efficacy of the novel dual PI3-kinase/mTOR inhibitor NVP-BEZ235 in a preclinical model of adrenocortical https://ec.bioscientifica.com https://doi.org/10.1530/EC-19-0224 (c) 2019 The authors Published by Bioscientifica Ltd
This work is licensed under a Creative Commons Attribution-NonCommercial-NoDerivatives 4.0 Internationab License.ifica com at $04 / 26 / 2023 \quad 07: 54: 39 \mathrm{Am}$ 
carcinoma. Molecular and Cellular Endocrinology 2012364 101-104. (https://doi.org/10.1016/j.mce.2012.08.014)

35 Liu P, Cheng H, Roberts TM \& Zhao JJ. Targeting the phosphoinositide 3-kinase pathway in cancer. Nature Reviews: Drug Discovery 20098 627-644. (https://doi.org/10.1038/nrd2926)

36 Altieri B, Colao A \& Faggiano A. The role of insulin-like growth factor system in the adrenocortical tumors. Minerva Endocrinologica 201944 43-57. (https://doi.org/10.23736/S0391-1977.18.02882-1)

37 Kurmasheva RT, Huang S \& Houghton PJ. Predicted mechanisms of resistance to mTOR inhibitors. British Journal of Cancer 200695 955-960. (https://doi.org/10.1038/sj.bjc.6603353)

38 Drelon C, Berthon A \& Val P. Adrenocortical cancer and IGF2: is the game over or our experimental models limited? Journal of Clinical Endocrinology and Metabolism 201398 505-507. (https://doi. org/10.1210/jc.2012-3310)

39 De Martino MC, Al Ghuzlan A, Aubert S, Assie G, Scoazec JY, Leboulleux S, Do Cao C, Libe R, Nozieres C, Lombès M, et al. Molecular screening for a personalized treatment approach in advanced adrenocortical cancer. Journal of Clinical Endocrinology and Metabolism 201398 4080-4088. (https://doi.org/10.1210/jc.20132165)

40 Fraenkel M, Gueorguiev M, Barak D, Salmon A, Grossman AB \& Gross DJ. Everolimus therapy for progressive adrenocortical cancer. Endocrine 201344 187-192. (https://doi.org/10.1007/s12020-0139878-1)

41 Barlaskar FM, Spalding AC, Heaton JH, Kuick R, Kim AC, Thomas DG, Giordano TJ, Ben-Josef E \& Hammer GD. Preclinical targeting of the type I insulin-like growth factor receptor in adrenocortical carcinoma. Journal of Clinical Endocrinology and Metabolism 200994 204-212. (https://doi.org/10.1210/jc.20081456)

42 Almeida MQ, Fragoso MC, Lotfi CF, Santos MG, Nishi MY, Costa MH, Lerario AM, Maciel CC, Mattos GE, Jorge AA, et al. Expression of insulin-like growth factor-II and its receptor in pediatric and adult adrenocortical tumors. Journal of Clinical Endocrinology and Metabolism 200893 3524-3531. (https://doi.org/10.1210/jc.2008$0065)$
43 Fassnacht M, Berruti A, Baudin E, Demeure MJ, Gilbert J, Haak H, Kroiss M, Quinn DI, Hesseltine E, Ronchi CL, et al. Linsitinib (OSI906) versus placebo for patients with locally advanced or metastatic adrenocortical carcinoma: a double-blind, randomised, phase 3 study. Lancet: Oncology 201516 426-435. (https://doi.org/10.1016/ S1470-2045(15)70081-1)

44 Naing A, Lorusso P, Fu S, Hong D, Chen HX, Doyle LA, Phan AT, Habra MA \& Kurzrock R. Insulin growth factor receptor (IGF-1R) antibody cixutumumab combined with the mTOR inhibitor temsirolimus in patients with metastatic adrenocortical carcinoma. British Journal of Cancer 2013108 826-830. (https://doi.org/10.1038/ bjc.2013.46)

45 Puglisi S, Perotti P, Cosentini D, Roca E, Basile V, Berruti A \& Terzolo M. Decision-making for adrenocortical carcinoma: surgical, systemic, and endocrine management options. Expert Review of Anticancer Therapy 201818 1125-1133. (https://doi.org/10.1080/147 37140.2018.1510325)

46 Terzolo M, Angeli A, Fassnacht M, Daffara F, Tauchmanova L, Conton PA, Rossetto R, Buci L, Sperone P, Grossrubatscher E, et al. Adjuvant mitotane treatment for adrenocortical carcinoma. New England Journal of Medicine 2007356 2372-2380. (https://doi. org/10.1056/NEJMoa063360)

47 Megerle F, Herrmann W, Schloetelburg W, Ronchi CL, Pulzer A, Quinkler M, Beuschlein F, Hahner S, Kroiss M, Fassnacht M, et al. Mitotane monotherapy in patients with advanced adrenocortical carcinoma. Journal of Clinical Endocrinology and Metabolism 2018103 1686-1695. (https://doi.org/10.1210/jc.2017-02591)

48 van Erp NP, Guchelaar HJ, Ploeger BA, Romijn JA, Hartigh Jd \& Gelderblom H. Mitotane has a strong and a durable inducing effect on CYP3A4 activity. European Journal of Endocrinology 2011164 621-626. (https://doi.org/10.1530/EJE-10-0956)

49 Juhlin CC, Goh G, Healy JM, Fonseca AL, Scholl UI, Stenman A, Kunstman JW, Brown TC, Overton JD, Mane SM, et al. Whole-exome sequencing characterizes the landscape of somatic mutations and copy number alterations in adrenocortical carcinoma. Journal of Clinical Endocrinology and Metabolism 2015100 E493-E502. (https:// doi.org/10.1210/jc.2014-3282)

Received in final form 30 July 2019

Accepted 8 August 2019

Accepted Preprint published online 9 August 2019 https://ec.bioscientifica.com https://doi.org/10.1530/EC-19-0224 (c) 2019 The authors Published by Bioscientifica Ltd
This work is licensed under a Creative Commons Attribution-NonCommercial-NoDerivatives 4.0 Internationab ticense.ifica com at $04 / 26 / 2023 \quad 07: 54: 39 \mathrm{AM}$ 